\title{
Linked publications from a single trial: a thread of evidence
}

\author{
Douglas G Altman ${ }^{1}$, Curt D Furberg ${ }^{2}$, Jeremy M Grimshaw ${ }^{3}$ and Daniel R Shanahan ${ }^{4 *}$
}

\section{Introduction}

Trials was launched with the ambition of providing authors with the opportunity to provide all the necessary detail for a true and complete scientific record [1]. It has long pushed for the communication of all outcome measures in health-related randomized controlled trials, as well as varying analyses and interpretations, and indepth descriptions of what was done and what was learnt. An integral part of this was, of course, the publication of study protocols, which had rarely been possible in paper-based journals [2]. A published protocol establishes precedence, allows more detailed discussion of methodological issues and can be referenced when reporting the main trial results [3].

The increasing publication of study protocols is undoubtedly one of Trials' greatest successes [4]. However, despite recent movements towards greater transparency in reporting research, concerns remain regarding the widespread discrepancies between trial publications and what was stated in the original study protocol $[5,6]$. Indeed, there is strong evidence that selective outcome reporting, with manipulation of the outcomes and analyses reported, is a common problem in medical research [7]. This serves to highlight the importance of researchers having access to all of the relevant information, to reliably evaluate bias or selective reporting in clinical trials.

However, while Trials regularly publishes the results of trials, primary trial reports are still predominantly published elsewhere. Although a results paper may reference a published study protocol, there is nothing to connect that report to subsequent publications; and no link from the protocol itself to the results article. This situation is further complicated by the ever-growing body of literature. A single clinical trial can result in multiple publications: the study protocol and traditional results

\footnotetext{
* Correspondence: daniel.shanahan@biomedcentral.com

${ }^{4}$ BioMed Central Ltd, 236 Gray's Inn Road, London WC1X 8HB, UK Full list of author information is available at the end of the article
}

paper or papers, as well as commentaries, secondary analyses and, eventually, systematic reviews, among others [8].

The advent of trial registration has helped to mitigate, to some extent, the lack of connectivity by providing a unique identifier associated with each trial record. However, while major medical journals typically capture the clinical trial number on or before publication, many do not follow Trials' example by publishing it in the abstract, as is recommended by CONSORT for Abstracts [9] and the International Committee of Medical Journal Editors (ICMJE) [10]. The reader thus has to identify related content through a literature search, using titles, authors and the abstract; details that will not necessarily remain consistent, as the articles may be published in different journals, with different authors, over many years.

\section{Threaded publications}

In 1999, Chalmers and Altman envisioned a solution. In their article in The Lancet, they wrote: 'Electronic publication of a protocol could be simply the first element in a sequence of "threaded" electronic publications, which continues with reports of the resulting research (published in sufficient detail to meet some of the criticisms of less detailed reports published in print journals), followed by deposition of the complete data set' [2]. This was the first description of the threaded publications initiative.

Building on the concept of trial registration, the aim of the threaded publications initiative is to link all publications relating to a single clinical trial centrally, regardless of journal or publisher, using the clinical trial number. This means that no matter which article in the 'thread' researchers start from, they will be easily able to identify and gain access to all other publications relating to that clinical trial. In 2011, we began to put this linkage into practice within Trials [11]; however, to achieve its fundamental aims, the project must go beyond a single journal or publisher.

It was in pursuit of this ambition that, in partnership with CrossRef, BioMed Central called a cross-publisher 
meeting to discuss how to build on the well-established digital-object identifier (DOI) and the more recent CrossMark tool, which provides information on the status of the associated article and an additional publication record, to achieve the threaded publications concept [12]. The meeting spurred the formation of a working group to govern the development of the project. Chaired by BioMed Central, the working group includes representatives from CrossRef, BMJ, Canadian Medical Associate Journal, the Cochrane Collaboration, eLife, F1000, the Internal Standard Randomized Controlled Trial Number (ISRCTN) Registry, The Lancet, Origin Editorial, the Public Library of Science, Springer, The Wellcome Trust and Wiley, and is overseeing the development of the first phase in the threaded publications concept, Linked Reports of Clinical Trials.

\section{Linked Reports of Clinical Trials}

The Linked Reports of Clinical Trials project will adapt the existing CrossMark standard to capture additional metadata about an article, namely the clinical trial number, the trial registry and the relation to the primary trial report, and associate that information with the article DOI on publication. A query to this CrossRef database will then return all articles related to that clinical trial number. As all the metadata will be open access (CC0 license) [13], with no copyright, it will be possible to access this article 'thread' either through the CrossMark interface or independently through an application programming interface (API).

A pilot evaluation of this system is set to begin towards the end of 2014, trialling how to adapt existing article workflows to capture these additional metadata prospectively and in an efficient and sustainable manner. For the initial pilot phase, only those articles for which the clinical trial number is currently required for publication by the publishers involved will be included; this includes study protocols [14] and updates [15], statistical analysis plans [16], primary results papers [17] and secondary analyses [18]. Following successful implementation on this subset, the scope will be expanded to capture the clinical trial number for additional article types related to clinical trials, such as case reports of adverse events, commentaries and editorials.

\section{Conclusion}

The medical literature is vast and it is impossible to keep up with the deluge of new research articles. With ongoing concerns regarding manipulation of the outcomes and analyses reported in medical research, it is increasingly important that researchers are able to easily identify and access all publications relating to a specific clinical trial, in order to obtain the complete picture and to evaluate bias or selective reporting reliably. Recent developments and innovations within the threaded publications initiative and the Linked Reports of Clinical Trials project demonstrate progress towards the ideal of making all trial information readily available.

\begin{abstract}
Abbreviations
CONSORT: Consolidated Standards of Reporting Trials; DOI: Digital-object identifier; ICMJE: International Committee of Medical Journal Editors; ISRCTN: Internal Standard Randomized Controlled Trial Number; API: Application programming interface.
\end{abstract}

\section{Competing interests}

DGA, CDF and JMG are Editors-in-Chief of Trials; DRS is an employee of BioMed Central Ltd, which publishes Trials.

\section{Authors' contributions}

DRS wrote the first draft of the manuscript. DGA, CDF and JMG were involved in review and critical revision of the content before publication. All authors read and approved the final manuscript.

\section{Author details}

${ }^{1}$ Centre for Statistics in Medicine, University of Oxford, Botnar Research Centre, Windmill Road, Oxford OX3 7LD, UK. ${ }^{2}$ Division of Public Health Sciences, Wake Forest University School of Medicine, Medical Center Boulevard, Winston-Salem, NC 27157-1063, USA. ${ }^{3}$ Clinical Epidemiology Programme, Ottawa Hospital Research Institute and Department of Medicine, University of Ottawa, 501 Smyth Road, Ottawa, ON K1H 8 L6, Canada.

${ }^{4}$ BioMed Central Ltd, 236 Gray's Inn Road, London WC1X 8HB, UK.

Received: 10 September 2014 Accepted: 10 September 2014 Published: 23 September 2014

\section{References}

1. Altman DG, Furberg CD, Grimshaw JM, Rothwell PM: Lead editorial. Trials - using the opportunities of electronic publishing to improve the reporting of randomised trials. Trials 2006, 7:6.

2. Chalmers I, Altman DG: How can medical journals help prevent poor medical research? Some opportunities presented by electronic publishing. Lancet 1999, 353:490-493.

3. Chan AW, Tetzlaff JM, Gøtzsche PC, Altman DG, Mann H, Berlin J, Dickersin K, Hróbjartsson A, Schulz KF, Parulekar WR, Krleža-Jerić K, Laupacis A, Moher D: SPIRIT 2013 explanation and elaboration: guidance for protocols of clinical trials. BMJ 2013, 346:e7586.

4. Altman DG, Hrynaszkiewicz I, Furberg CD, Grimshaw JM, Rothwell PM: Five years of Trials. Trials 2011, 12:248.

5. Dwan K, Altman DG, Cresswell L, Blundell M, Gamble CL, Williamson PR: Comparison of protocols and registry entries to published reports for randomised controlled trials. Cochrane Database Syst Rev 2011, MR000031.

6. Dwan K, Altman DG, Clarke M, Gamble C, Higgins JP, Sterne JA, Williamson PR, Kirkham JJ: Evidence for the selective reporting of analyses and discrepancies in clinical trials: a systematic review of cohort studies of clinical trials. PLoS Med 2014, 11:e1001666.

7. Chan AW, Hrobjartsson A, Haahr MT, Gotzsche PC, Altman DG: Empirical evidence for selective reporting of outcomes in randomized trials: comparison of protocols to published articles. JAMA 2004, 291:2457-2465.

8. Cochrane J: The Third International Stroke Trial (IST-3) - an exemplary threaded publication? http://blogs.biomedcentral.com/bmcblog/2012/05/ 25/the-third-international-stroke-trial-ist-3-an-exemplary-threadedpublication/.

9. Hopewell S, Clarke M, Moher D, Wager E, Middleton P, Altman DG, Schultz KF, the CONSORT Group: CONSORT for reporting randomized controlled trials in journal and conference abstracts: explanation and elaboration. PLoS Med 2008, 5:e20.

10. International Committee of Medical Journal Editors: ICMJE Recommendations for the Conduct, Reporting, Editing and Publication of Scholarly Work in Medical Journals (ICMJE Recommendations). http:// www.icmje.org/recommendations/browse/publishing-and-editorial-issues/ clinical-trial-registration.html. 
11. Hrynaszkiewicz l: Towards threaded publications: helping to set the scientific record straight. http://blogs.biomedcentral.com/bmcblog/2011/01/ 14/towards-threaded-publications-helping-to-set-the-scientific-record-straight/.

12. Shanahan DR: Threaded publications: one step closer. http://blogs. biomedcentral.com/bmcblog/2014/01/31/threaded-publications-onestep-closer/.

13. Creative Commons CCO 1.0 Universal (CCO 1.0): Public Domain Dedication. http://creativecommons.org/publicdomain/zero/1.0/.

14. Sandercock $P$, Lindley $R$, Wardlaw J, Dennis $M$, Lewis $S$, Venables $G$, Kobayashi A, Czlonkowska A, Berge E, Slot KB, Murray V, Peeters A, Hankey G, Matz K, Brainin M, Ricci S, Celani MG, Righetti E, Cantisani T, Gubitz G, Phillips S, Arauz A, Prasad K, Correia M, Lyrer P, the IST-3 Collaborative Group: Third international stroke trial (IST-3) of thrombolysis for acute ischaemic stroke. Trials 2008, 9:37.

15. Sandercock P, Lindley R, Wardlaw J, Dennis M, Innes K, Cohen G, Whiteley W, Perry D, Soosay V, Buchanan D, Venables G, Czlonkowska A, Kobayashi A, Berge E, Slot KB, Murray V, Peeters A, Hankey GJ, Matz K, Brainin M, Ricci S, Cantisani TA, Gubitz G, Phillips SJ, Antonio A, Correia M, Lyrer P, Kane I, Lundstrom E, the IST-3 Collaborative Group: Update on the third international stroke trial (IST-3) of thrombolysis for acute ischaemic stroke and baseline features of the 3035 patients recruited. Trials 2011, 12:252.

16. Sandercock P, Lindley R, Wardlaw J, Whiteley W, Murray G, the IST-3 Collaborative Group: Statistical analysis plan for the third International Stroke Trial (IST-3); part of a 'thread' of reports of the trial. Int I Stroke 2012, 7(3):186-187.

17. Sandercock P, Wardlaw JM, Lindley RI, Dennis M, Cohen G, Murray G, Innes K, Venables G, Czlonkowska A, Kobayashi A, Ricci S, Murray V, Berge E, Slot KB, Hankey GJ, Correia M, Peeters A, Matz K, Lyrer P, Gubitz G, Phillips SJ, Arauz A, the IST-3 Collaborative Group: The benefits and harms of intravenous thrombolysis with recombinant tissue plasminogen activator within $6 \mathrm{~h}$ of acute ischaemic stroke (the third international stroke trial [IST-3]): a randomised controlled trial. Lancet 2012, 379(9834):2352-2363.

18. IST-3 Collaborative Group: Effect of thrombolysis with alteplase within $6 \mathrm{~h}$ of acute ischaemic stroke on long-term outcomes (the third International Stroke Trial [IST-3]): 18-month follow-up of a randomised controlled trial. Lancet Neurol 2013, 12(8):768-776.

doi:10.1186/1745-6215-15-369

Cite this article as: Altman et al:: Linked publications from a single trial: a thread of evidence. Trials 2014 15:369.

\section{Submit your next manuscript to BioMed Central and take full advantage of:}

- Convenient online submission

- Thorough peer review

- No space constraints or color figure charges

- Immediate publication on acceptance

- Inclusion in PubMed, CAS, Scopus and Google Scholar

- Research which is freely available for redistribution 